\title{
Evolution of the Banff Working Classification of Renal Allograft Pathology: Updates and Future Directions
}

\author{
Muhammed Mubarak ${ }^{1 *}$ and Javed I. Kazi \\ ${ }^{1}$ Department of Pathology Sindh Institute of Urology and Transplantation (SIUT) Karachi, Pakistan \\ ${ }^{2}$ Histopathology Department, Sindh Institute of Urology and Transplantation (SIUT) Karachi, Pakistan
}

\begin{abstract}
Renal transplant pathology is a complex and rapidly evolving field of surgical pathology and the pathologic interpretation of renal allograft biopsy pose significant challenges and opportunities to the renal transplant pathologists. Both allo-immune and non-immune factors often interplay in causing damage to the kidney allograft at different time intervals post-transplantation. An accurate identification of these etiologic factors is essential for the optimal management and better long-term outcome of the renal transplant patients and the biopsy plays a pivotal role in this process. The Banff classification was introduced as an international, consensus-based working formulation to harmonize the reporting of pathological lesions seen on renal allograft biopsies. The first meeting of the Banff group took place in 1991 and the first detailed publication on the classification appeared in 1993. Subsequent meetings have been held regularly every two years with regular updates, additions and revisions of the original classification. The latest meeting was held in Brazil this year (2013) and its detailed reporting is still due.
\end{abstract}

This editorial attempts to summarize the main changes that have taken place in the interpretation of renal allograft biopsy pathology and the Banff classification over the last two decades. The main focus of the paper will be on the evolution of the morphological and immunohistochemical changes, as these are still the mainstay of the Banff classification. The standardization and incorporation of the formal morphometric and molecular data into the Banff classification for practical use is still a challenge for the future.

Keywords: Antibody-mediated rejection; Banff schema; evolution; T cells; Transplantation

Renal transplantation is the treatment of choice for patients with End-Stage Renal Disease (ESRD) worldwide [1]. Numerous advancements and technical innovations in the field of organ transplantation during the last few decades have revolutionized the approaches to the problems faced by the transplant community [2]. However, many formidable challenges still remain, hampering the widespread use of this modality of Renal Replacement Therapy (RRT) throughout the world [1-4].

One of the important challenges after renal transplantation is the accurate identification and appropriate management of the graft dysfunction $[2,3]$. The causes of dysfunction vary depending on many factors, including the time post-transplant, type of immunosuppression used, living vs. cadaveric origin of the organ, and so on [4]. These often require recourse to the invasive procedure of renal allograft biopsy, which is still the gold standard test for an accurate diagnosis and categorization of rejection, for example [3]. The safety and clinical utility of the biopsy has been proved beyond doubt in numerous clinical studies during the last few decades [5-11]. However, the pathological interpretation of the biopsies is a daunting task and fraught with interobserver variation. Moreover, the pathology of transplantation is continuously evolving [12-17]. The Banff classification was introduced to address the above issues in the reporting of renal transplant pathology and to harmonize the reporting of the lesions in a uniform language, which is understood by the clinicians, pathologists, basic scientists and transplant surgeons alike $[12,17]$. The first meeting of the Banff group took place in 1991 at Banff, Canada and the first detailed publication appeared in 1993 [12,15,17]. Since then, regular meetings of the ever expanding group have been held every two years with timely updates, additions and revisions of the original classification. The aim of these meetings has been to revisit and refine the original classification in the light of accumulating new research and evidence from ongoing studies [12, 17-19].

The first major change occurred in the Banff 1997 meeting with the merger of the then two popular classifications, i.e., Banff 93-95 and the
Collaborative Clinical Trials in Transplantation (CCTT) modification of Banff classification. Many of the concepts of CCTT classification were accommodated in Banff 97 classification. However, the basic construct and the semiquantitative scoring of the lesions were not changed, as were the original diagnostic categories of Banff 93-95 [17-19].

Regarding individual diagnostic categories, major changes have occurred in the categories of antibody-mediated rejection, T-CellMediated Rejection (TCMR) and chronic allograft changes. Some of these evolutionary changes in the diagnostic approach have been reviewed in detail by this author elsewhere [13]. Briefly, the most spectacular changes have taken place in the category of ABMR [13]. The detailed pathology-based diagnostic criteria have been devised and updated for an accurate diagnosis and categorization of ABMR into acute and chronic active categories. The major impetus for this surge in interest in ABMR has been provided by the discovery and the widespread use of $c 4 \mathrm{~d}$ as a biomarker for ABMR [20-22]. A subtype of ABMR, c4d-negative ABMR has been recognized and a Banff Working Group established to devise the evidence-based criteria of this subtype and to determine the full impact of allo-antibodies on the kidney allograft. A correlation has been found between ABMR diagnosed by histological criteria and molecular profiling. Further work is needed before these diagnostic modalities are merged smoothly into a workable classification [23-28].

*Corresponding author: Prof Dr Muhammed Mubarak Professor of Pathology Histopathology Department, Sindh Institute of Urology and Transplantation, Karachi 74200, Pakistan, Tel: 00922199215752; Fax: 00922132726165; E-mail drmubaraksiut@yahoo.com

Received October 11, 2013; Accepted October 18, 2013; Published October 25 2013

Citation: Mubarak M, Kazi JI (2013) Evolution of the Banff Working Classification of Renal Allograft Pathology: Updates and Future Directions. J Transplant Techno Res 3: e126. doi:10.4172/2161-0991.1000e126

Copyright: (c) 2013 Mubarak M, et al. This is an open-access article distributed under the terms of the Creative Commons Attribution License, which permits unrestricted use, distribution, and reproduction in any medium, provided the original author and source are credited. 
Concomitant with the changes in ABMR category, changes also occurred in the category of active/acute rejection, which has been renamed as TCMR and divided into acute and chronic active categories, as for the ABMR [25-28]. The diagnostic criteria of the chronic active TCMR are still poorly characterized [26].

The most formidable challenge in the field of renal transplantation today is the progressive development of chronic changes in the allograft. The diagnosis, classification and grading of the chronic changes is equally important in guiding management and predicting the longterm graft outcome. Prior to 1991, the term "chronic rejection" was in widespread use for all causes of chronic allograft dysfunction. The Banff formulation introduced the term Chronic Allograft Nephropathy (CAN) as a descriptive alternative to the misleading term of "Chronic Rejection". Banff 93 classification divided CAN into three grades based on the degree of tubular atrophy and interstitial fibrosis. No subdivision of CAN was made and all causes of chronic changes were lumped together in this category. In Banff 1995 meeting, Chronic Allograft Nephropathy Index (CADI) was integrated with the CAN category to grade the severity of the chronic changes $[11,16]$. In Banff 97 classification, a subdivision of each of the grades into "a" and "b" categories was done depending on the absence or presence of specific features related to "Chronic Rejection". However, the grading of the CAN was not changed [17]. No modifications in CAN category were made in 97-update classification or Banff 2003 meeting reports. A major change in the category of chronic changes occurred in Banff 2005 meeting when the term CAN was eliminated and replaced by Interstitial Fibrosis/Tubular Atrophy (IFTA), no evidence of specific etiology [25]. The causes of "a" subcategory of CAN in previous classifications were moved to the "other" category, while the chronic allo-immune injuries were included in the respective categories of ABMR and TCMR. Thus, the category 5 in the Banff 2005 and onwards now includes only those cases of chronic changes in which no specific features of causal factors are found on the biopsy.

A more recent and innovative development is the establishment of international Banff Working Groups (BWGs) to conduct multicenter trials, collect data and produce evidence-based guidelines for revision and refinement of diagnostic criteria in the problematic areas of renal transplant pathology $[27,28]$.

In conclusion, the Banff classification has become the major force for the uniform and standardized reporting of the pathological lesions on renal allograft biopsies through out the world. The Banff classification is, by default, a flexible formulation and has undergone considerable evolution over the last two decades and much progress is still awaited.

\section{References}

1. Meier-Kriesche HU, Schold JD, Kaplan B (2004) Long-term renal allograft survival: have we made significant progress or is it time to rethink our analytic and therapeutic strategies? Am J Transplant 4: 1289-1295.

2. El-Zoghby ZM, Stegall MD, Lager DJ, Kremers WK, Amer H, et al. (2009) Identifying specific causes of kidney allograft loss. Am J Transplant 9: 527-535.

3. John R, Herzenberg AM (2010) Our approach to a renal transplant biopsy. J Clin Pathol 63: 26-37.

4. Mubarak M. Practicing renal transplant pathology in a developing country: Challenges and opportunities. J Transplant Technol Res 2012; 2:4.

5. Kazi J, Mubarak M. Biopsy findings in renal allograft dysfunction in a live related renal transplant program. J Transplant Tech Res 2012; 2:108.

6. Matas AJ, Sibley R, Mauer M, Sutherland DE, Simmons RL, et al. (1983) The value of needle renal allograft biopsy. I. A retrospective study of biopsies performed during putative rejection episodes. Ann Surg 197: 226-237.
7. Parfrey PS, Kuo YL, Hanley JA, Knaack J, Xue Z, et al. (1984) The diagnostic and prognostic value of renal allograft biopsy. Transplantation 38: 586-590.

8. Matas AJ, Tellis VA, Sablay L, Quinn T, Soberman R, et al. (1985) The value of needle renal allograft biopsy. III. A prospective study. Surgery 98: 922-926.

9. Gaber LW (1998) Role of renal allograft biopsy in multicenter clinical trials in transplantation. Am J Kidney Dis 31: S19-25.

10. Al-Awwa IA, Hariharan S, First MR (1998) Importance of allograft biopsy in renal transplant recipients: correlation between clinical and histological diagnosis. Am J Kidney Dis 31: S15-18.

11. Pascual M, Vallhonrat $H$, Cosimi AB, Tolkoff-Rubin N, Colvin RB, et al. (1999) The clinical usefulness of the renal allograft biopsy in the cyclosporine era: a prospective study. Transplantation 67: 737-741.

12. Solez K (2010) History of the Banff classification of allograft pathology as it approaches its 20th year. Curr Opin Organ Transplant 15: 49-51.

13. Mubarak M, Kazi JI. Evolution of the diagnostic criteria of antibody-mediated rejection of renal allografts: Banff classification updates. Port J Nephrol Hypert 2013; $27: 137-42$.

14. Serón D, Anaya F, Marcén R, del Moral RG, Martul EV, et al. (2008) [Guidelines for indicating, obtaining, processing and evaluating kidney biopsies]. Nefrologia 28: 385-396.

15. Solez K, Axelsen RA, Benediktsson H, Burdick JF, Cohen AH, et al. Internationa standardization of criteria for the histologic diagnosis of renal allograft rejection: the Banff working classification of kidney transplant pathology. Kidney Int 1993; 44: 411-22.

16. Weening JJ (2008) The art of classifying renal allograft pathology. Nat Clin Pract Nephrol 4: 420-421.

17. Solez K, Racusen LC (2013) The Banff classification revisited. Kidney Int 83 201-206.

18. Racusen LC, Solez K, Colvin RB, Bonsib SM, Castro MC, et al. (1999) The Banff 97 working classification of renal allograft pathology. Kidney Int 55: 713723.

19. Colvin RB, Cohen AH, Saiontz C, Bonsib S, Buick M, et al. (1997) Evaluation of pathologic criteria for acute renal allograft rejection: reproducibility, sensitivity and clinical correlation. J Am Soc Nephrol 8: 1930-1941.

20. Feucht HE, Felber E, Gokel MJ, Hillebrand G, Nattermann U, et al. (1991) Vascular deposition of complement-split products in kidney allografts with cellmediated rejection. Clin Exp Immunol 86: 464-470.

21. Mauiyyedi S, Pelle PD, Saidman S, Collins AB, Pascual M, et al. (2001) Chronic humoral rejection: identification of antibody-mediated chronic renal allograft rejection by $\mathrm{C} 4 \mathrm{~d}$ deposits in peritubular capillaries. J Am Soc Nephro 12: $574-582$

22. Mauiyyedi S, Crespo M, Collins AB, Schneeberger EE, Pascual MA, et al (2002) Acute humoral rejection in kidney transplantation: II. Morphology, immunopathology, and pathologic classification. J Am Soc Nephrol 13: 779787.

23. Racusen LC, Colvin RB, Solez K, Mihatsch MJ, Halloran PF, et al. (2003) Antibody-mediated rejection criteria - an addition to the Banff 97 classification of renal allograft rejection. Am J Transplant 3: 708-714

24. Racusen LC, Halloran PF, Solez K (2004) Banff 2003 meeting report: new diagnostic insights and standards. Am J Transplant 4: 1562-1566.

25. Solez K, Colvin RB, Racusen LC, Sis B, Halloran PF, et al. (2007) Banff '05 Meeting Report: differential diagnosis of chronic allograft injury and elimination of chronic allograft nephropathy ('CAN'). Am J Transplant 7: 518-526.

26. Solez K, Colvin RB, Racusen LC, Haas M, Sis B, et al. (2008) Banff 07 classification of renal allograft pathology: updates and future directions. Am J Transplant 8: 753-760.

27. Sis B, Mengel M, Haas M, Colvin RB, Halloran PF, et al. (2010) Banff '09 meeting report: antibody mediated graft deterioration and implementation of Banff working groups. Am J Transplant 10: 464-471.

28. Mengel M, Sis B, Haas M, Colvin RB, Halloran PF, et al. (2012) Banff 2011 Meeting report: new concepts in antibody-mediated rejection. Am J Transplant 12: $563-570$. 